National Marine

Fisheries Service

Fishery Bulletin

Spencer F. Baird

NOAA

क established in 1881 ๙

First U.S. Commissione

of Fisheries and founder

of Fishery Bulletin

\begin{abstract}
Commercial fishing exposes Pacific halibut (Hippoglossus stenolepis) to a myriad of stressors during capture, processing, and discarding, including exposure to direct sunlight that causes diminished retinal sensitivity. It is unknown, however, whether recovery occurs. We therefore employed both electroretinography and a behavioral assay to measure recovery of retinal sensitivity and visual function in halibut exposed to $15 \mathrm{~min}$ of simulated sunlight. We used electroretinography to measure changes in retinal light sensitivity after recovery periods of $2,4,6$ and 10 weeks and a behavioral assay to measure responsiveness to simulated prey (i.e., in behavioral trials) to measure visual function after recovery periods of 2 to $6 \mathrm{~d}$. Exposure to simulated sunlight significantly reduced retinal sensitivity to light with no apparent recovery after 10 weeks. Although retinal sensitivity was reduced, fish exposed to direct sunlight displayed no demonstrable deficits in visual function during behavioral trials.
\end{abstract}

Manuscript submitted 24 January 2017. Manuscript accepted 7 September 2017. Fish. Bull. 115:566-575 (2017).

Online publication date: 20 September 2017. doi: 10.7755/FB.115.4.12

The views and opinions expressed or implied in this article are those of the author (or authors) and do not necessarily reflect the position of the National Marine Fisheries Service, NOAA.

\title{
Recovery of visual function in Pacific halibut (Hippoglossus stenolepis) after exposure to bright light
}

\author{
Christopher Magel (contact author) ${ }^{1}$ \\ Clifford Ryer ${ }^{1}$ \\ Richard Brill2 \\ Email address for contact author: chris.magel@noaa.gov \\ 1 Alaska Fisheries Science Center \\ National Marine Fisheries Service, NOAA \\ 2030 S. Marine Science Drive, Building RSF951 \\ Newport, Oregon 97365-5296 \\ 2 Northeast Fisheries Science Center \\ National Marine Fisheries Service, NOAA \\ P.O. Box 1346 \\ Gloucester Point, Virginia 23062-1346
}

One-quarter of the catch of worldwide fisheries comprises nontarget species (i.e., as bycatch or incidental catch) that are often discarded (Alverson et al., 1994). Fish may be dead when discarded, or may subsequently expire as a consequence of physical injury and stress incurred during capture and release. Mortality rates for discarded fish are, however, rarely known and represent a large source of uncertainty in fisheries models (Davis, 2002). In some instances, compromised fish succumb to predation hours or days after being discarded (Davis, 2002). For example, juvenile walleye pollock (Gadus chalcogrammus) and sablefish (Anoplopoma fimbria) subjected to stressors simulating escape through trawl codend meshes have been shown to be more vulnerable than control fish to predation in staged predator encounters (Ryer, 2002, 2004). In other instances, fish may recover but experience lower fitness as a consequence of injuries or stress. Atlantic cod ( $G a$ dus morhua) stressed through simulated trawl avoidance produced poor quality eggs and larvae (Morgan et al., 1999); and sockeye salmon (Oncorhynchus nerka) that escaped gill nets incurred physical injuries and physiological impairments that reduced spawning success by 50\% (Baker and Schindler, 2009). Reduced growth and body size may also impact reproduction. Using a bioenergetics model, Meka and Margraf (2007) estimated that catch-and-release can reduce growth of rainbow trout (Oncorhynchus mykiss) up to $15 \%$ when there is no physical injury, and up to $164 \%$ where debilitating hook injuries are incurred. Although these studies have documented outcomes of bycatch stress, they rarely address the mechanisms that cause the stress. In particular, scant information exists on how capture and release may impair sensory systems such as vision, which fish rely on to locate food and avoid predation.

Pacific halibut (Hippoglossus stenolepis) are captured in trawl and longline fisheries targeting groundfishes along the contiguous United States and Canada (Davis and Olla, 
2001). Trawl fisheries are, however, required to discard all Pacific halibut, thus subjecting a significant portion of the Bering Sea and Gulf of Alaska population to capture stress (Williams and Wilderbuer ${ }^{1}$ ). Methods to determine health and condition of Pacific halibut destined for discard are based on the physical condition of the fish and variables related to the actual fishing process (Kaimmer and Trumble, 1998). Information on fish condition, stress, and variables related to the fishing process are collected by fisheries observers, but these data can vary greatly owing to subjective differences in assessment of fish condition and trawl tow characteristics (e.g., catch weight, depth of tow, tow speed) (Pikitch et al. ${ }^{2}$ ). Therefore, the amount of time on deck may be a better indicator of condition at release than the means of capture (i.e., trawl or longline) (Davis and Schreck, 2005)

Recent studies indicate that Pacific halibut biomass remains relatively stable, although recruitment remains weak (Stewart and Hicks ${ }^{3}$ ), and bycatch mortality is approximately $20 \%$ within directed groundfish fisheries (Benaka et al., 2014). Also, bycatch has been slowly decreasing, although rates fluctuate depending on the location of the fishery itself (Dykstra ${ }^{4}$ ). Continued reductions in bycatch mortality could be facilitated by a better understanding of both the physiological and behavioral mechanisms that are compromised at the time of release of bycatch and affect survival.

Pacific halibut are visual predators (Hurst et al., 2007) and frequently live in turbid coastal waters at depths ranging from 90 to $900 \mathrm{~m}$ (i.e., on the continental shelf) (IPHC ${ }^{5}$ ) and therefore under low ambient light levels. After capture in trawl fisheries, individual fish are often left on deck for tens of minutes before they are discarded (Trumble et al., 1995; Davis and Olla, 2001). During this time, they can be exposed to direct sunlight (i.e., at light levels orders of magnitude above ambient levels on the seafloor) that potentially

1 Williams, G. H., and T. Wilderbuer. 1992. Revised estimates of Pacific halibut discard mortality rates in the 1990 groundfish fisheries off Alaska. In Int. Pac. Halibut Comm. report of assessment and research activities 1991, p. 191-209. Int. Pac. Halibut Comm., Seattle, WA. [Available from website.]

2 Pikitch, E. K., D. L. Erickson, C. K. Mitchell, and J. R. Wallace. 1997. Practical applications of fishing and handling techniques in estimating the mortality of discarded trawlcaught Pacific halibut (Hippoglossus stenolepis). ICES C.M. 1997/FF:05, 18 p. [Available from website.]

3 Stewart, I. J., and A. C. Hicks. 2017. Assessment of the Pacific halibut stock at the end of 2016. In Int. Pac. Halibut Comm. report of assessment and research activities 2006 . IPHC-2016-RARA-26-R, p. 365-394. Int. Pac. Halibut Comm., Seattle, WA. [Available from website.]

${ }^{4}$ Dykstra, C. L. 2017. Incidental catch and mortality of Pacific halibut, 1990-2016. In Int. Pac. Halibut Comm. report of assessment and research activities 2006. IPHC-2016RARA-26-R, p. 71-89. Int. Pac. Halibut Comm., Seattle, WA. [Available from website.]

${ }^{5}$ IPHC (International Pacific Halibut Commission). 1998. The Pacific halibut: biology, fishery, and management. Tech. Rep. 40, 64 p. Intl. Pac. Halibut Comm., Seattle, WA. [Available from website.] causes impaired visual function (Loew, 1976; MeyerRochow, 1994; Wu et al., 2006). Previous research has documented a reduction in retinal sensitivity to light in Pacific halibut after 15 min of exposure to simulated sunlight (Brill et al, 2008). This reduction in sight could have consequences for foraging success after release by diminishing the ability of a fish to perceive and capture prey. It is unknown, however, whether this deficit is permanent or whether it reduces the ability of Pacific halibut to detect and capture prey. Our objective was to extend previous research (Brill et al., 2008) and to assess specifically whether retinal sensitivity and overall visual function can recover after exposure to simulated sunlight.

We addressed these objectives by using both electroretinography (ERG) and behavioral methods. ERG measures the summed potential of electrical signals within the retina, providing a technique for rapidly and quantitatively assessing retinal function (Brown, 1968). An evaluation of the behavior of Pacific halibut subjected to bright light, namely an evaluation of their ability to accomplish essential tasks, such as perceiving and capturing prey, will help determine the effects of bycatch on somatic growth, fecundity, and survival.

\section{Materials and methods}

All fish capture, maintenance, handling, and experimental procedures followed accepted protocols and were in compliance with all relevant laws and regulation. Age-0 Pacific halibut (40-70 $\mathrm{mm}$ in total length [TL]) were acquired by trawl net in Chiniak Bay, Kodiak Island, Alaska $\left(57^{\circ} 40^{\prime} \mathrm{N}, 152^{\circ} 30^{\prime} \mathrm{W}\right)$ and delivered to the Hatfield Marine Science Center, Newport, Oregon. Pacific halibut were kept in 3.1-m diameter fiberglass tanks (at a 1-m depth) with flowing seawater at $8-10^{\circ} \mathrm{C}$ degrees for 2 or 3 years before use in the experiments. The tanks were maintained under lowillumination fluorescent lighting (photon flux density of $0.01 \mu \mathrm{mol} \cdot \mathrm{m}^{-2} \cdot \mathrm{s}^{-1}$ ) and day time and night time were set on a 12 -h photoperiod. Fish were fed 3 times per week during the first year and twice per week during the second year with a gel food consisting of gelatin, vitamins, amino acid supplements, krill (Euphausia superba), pelleted food, Pacific herring (Clupea pallasii), and squid.

\section{Exposure to bright light}

Individual 2-year-old Pacific halibut (13-17 cm TL) fish were lifted by dip net from their holding tank, lightly anesthetized with a tricaine methanosufonate (Tricaine$\mathrm{S}^{6}$ [MS-222], Western Chemical, Inc., Ferndale, WA) solution of $\sim 5 \mathrm{mg} / \mathrm{L}$ to reduce movement and stress, and held in a shallow seawater bath $\left(12^{\circ} \mathrm{C}\right)$. They were

\footnotetext{
${ }^{6}$ Mention of trade names or commercial companies is for identification purposes only and does not imply endorsement by the National Marine Fisheries Service, NOAA.
} 
then exposed to simulated sunlight for $15 \mathrm{~min}$ by using a light source and a fiber optic guide aimed at the right eye of a fish. The left eye was covered with a lightblocking cloth. The 15-min simulated sunlight exposure was chosen to correspond with the time fish are left on deck during commercial trawl sorting operations (Davis and Olla, 2001; Davis and Schreck, 2005). Control fish were treated in kind, except that the light source was not turned on. Fish were subsequently returned to their holding tanks and separated with a barrier to allow both control and light exposed fish to be held under identical conditions.

Sunlight was simulated by using a high-intensity xenon lamp (Spectral Products, Putnam, CT) and its spectral range was $\sim 320-700 \mathrm{~nm}$, which approximates the visible (400-700 $\mathrm{nm}$ ) and the UV range of sunlight directly overhead at sea level (Lalli and Parsons, 1997). Light intensity exiting the fiber optic light guide was $\sim 2000 \mathrm{\mu mol} \cdot \mathrm{m}^{-2} \cdot \mathrm{s}^{-1}$ (measured over $400-700 \mathrm{~nm}$ of spectral range) and simulated sunlight $\left(2010 \mu \mathrm{mol} \cdot \mathrm{m}^{-2} \cdot \mathrm{s}^{-1}\right)$ and measured at Newport, Oregon, under ideal clear conditions at 1200 noon PST on 5 October 2007 and by using a IL 1700 Research Radiometer (International Light Technologies, Inc., Peabody, MA) equipped with a photosynthetically active radiation-filtered waterproof sensor.

\section{Evaluation of visual function with the use of an ERG}

To evaluate visual function by using ERG, fish were moved into a dark room in a light-proof container. Individuals were then lightly anesthetized with a buffered MS-222 solution ( 5-mg/L) and the neuromuscular blocking drug gallamine triethiodide (Flaxedil, Sigma Chemical Co., St. Louis, MO, dose $\sim 20 \mathrm{mg} / \mathrm{kg}$ ) injected into the caudal vein to reduce movement. Fish were then placed on a sling and enclosed in a light-blocking container placed in an acrylic box. The body of the fish was submerged in a manner such that only a small portion of the head and the eye would remain above water to receive the light stimulus. The container was supplied with flow-through seawater $\left(12^{\circ} \mathrm{C}\right)$ and the gills of the fish remained aerated by means of a small submersible pump for water circulation. Fish were adapted to darkness for a minimum of $1 \mathrm{~h}$ before physiological measurements were taken.

Teflon-coated silver wire electrodes with a silver chloride electroplated coating, were used to record the ERG responses The recording electrode was placed lightly on the corneal surface and the reference electrode was placed on the skin over the head of the fish. The recording chamber was illuminated with a dim red light (peak wavelength $660 \mathrm{~nm}$ ) produced by light-emitting diodes (LEDs); these remained on while the electrodes were positioned. The recording system was grounded by using a stainless-steel plate within the experimental apparatus. ERG signals were amplified $(10,000 \times$ gain) with $1-\mathrm{Hz}$ high pass and $1-\mathrm{kHz}$ low-pass filter settings on a DAM50 amplifier (World Precision Instruments, Inc., Sarasota, FL). The signal was also filtered with a HumBug active electronic noise eliminator (Quest Scientific Instruments, Inc., North Vancouver, Canada) that removed $60-\mathrm{Hz}$ noise and was digitized at a $1-\mathrm{kHz}$ sampling frequency with a multifunction data acquisition card (DAQCard-6024E, National Instruments Corp., Austin, TX). Light stimuli and all data were controlled by a custom program developed by Eric Warrant (University of Lund, Lund, Sweden) for use in the LabVIEW graphical programming system for measurement and automation (National Instruments Corp.).

A circular (3.8-cm diameter) light source (SL2420 spot light, Advanced Illumination, Inc., Rochester, VT) was used to produce a white LED light stimulus, and a thin diffuser and collimating lens were used to produce an even field of illumination $( \pm 10 \%)$. An intensity controller (CS410, Advanced Illumination, Inc.) was used to control light output. The intensity controller was connected and controlled by the analog output of the data acquisition card. To extend the range of available light levels, a series of neutral density filters (Kodak Optical Products, Eastman Kodak Co., Rochester, NY) were used to dim the light stimulus.

As in previous studies (e.g., Brill et al., 2008), we examined changes in retinal sensitivity to light resulting from exposure to simulated sunlight by recording the summed potential of electrical signal in response (in volts [V]) to a range of light intensities (I) and subsequently used the data to construct voltage in relation to log light intensity response curves (V-log I). Light intensities were increased by 0.2 log-unit steps from a level with no measurable response, to a level that produced a max response. A light stimulus consisted of a train of five 200-ms light flashes delivered $200 \mathrm{~ms}$ apart. This stimulus was presented every $5 \mathrm{~s}$ and repeated 5 times at each light intensity. The ERG responses to the final flash of each train were recorded and averaged. At the conclusion of an experiment, fish were euthanized with either a massive overdose $(>300$ $\mathrm{mg} / \mathrm{kg}$ ) of sodium pentobarbital (Beuthanasia-D, Merck Animal Health, Madison, NJ) injected into the caudal vein, or by immersion in a bath of clove oil where the clove oil solution was circulated over the gills by a small submersible pump.

Initially, we compared ERG data for the left and right eyes of control fish $(n=4)$ that had not been exposed to simulated sunlight. Preliminary analysis indicated that right eyes produced a consistently stronger voltage signal than left eyes. Our original intention had been to use unexposed left eyes as 'within-fish' controls for the exposed right eyes in the exposure recovery experiment. However, because of the difference in signal strength between left and right eyes, we abandoned this strategy and relied instead upon a comparison of right eyes between control fish and sunlight exposed fish after various periods of recovery. Fish exposed to simulated sunlight were divided in groups with recovery times of $2,4,6$, and 10 weeks. Each group consisted of $8-10$ individuals.

In addition to voltage response data we also calculated voltage percent maximum (p-max) data; for each 
fish, namely the percentage of maximal response at each tested light intensity. Finally, the data from each individual ERG curve was fitted by using a second-order polynomial equation with SYSTAT software, vers. 13 (Systat Software, Inc., San Jose, CA) or Microsoft Office 2013 (Microsoft Corp., Redmond, WA), because the ERG response curves generally were of a sigmoid shape. To provide a summary measure of visual impairment, we calculated log-scale illumination required to produce a 50\% p-max response from each fish. In the left and right eye, and exposure recovery experiments, ERG responses presented as voltages and pmax responses were examined with repeated measures analysis of variance (ANOVA) (Sokal and Rohlf, 1969). For examination of the light level required to produce a 50\% p-max response, we compared treatment groups, using one-way ANOVA (Sokal and Rohlf, 1969). Where appropriate, we employed a Tukey's honestly significant difference (HSD) test (Sokal and Rohlf, 1969) to examine differences in treatment means. Tests were considered significant at the $P<0.05$ level.

\section{Behavioral evaluation of fish in relation to visual function}

Individual 3-year-old Pacific halibut (21-27 cm TL) were anesthetized with MS-222 as described above, but in this case both eyes were subjected to a 15-min exposure to simulated sunlight before behavioral experiments. After light exposure, pairs of fish were moved into 1.9 -m diameter $\times 80-\mathrm{cm}$ deep circular tanks to recover. The tanks were located within a light-controlled laboratory and supplied with constantly flowing seawater at $\sim 9^{\circ} \mathrm{C}$.

Experiments were conducted with 8-10 pairs of fish at six light intensities simulating environmental conditions typical for Pacific halibut ( 90-900 m): $1 \times 10^{-3}$, $1 \times 10^{-4}, 1 \times 10^{-5}$, and $1 \times 10^{-6}, 1 \times 10^{-7} \mathrm{\mu mol} \cdot \mathrm{m}^{-2} \cdot \mathrm{s}^{-1}$, and complete darkness $\left(<0.01 \times 10^{-7}\right)$. Light levels were measured on the bottom of the experimental tank with a IL1700 Research Radiometer equipped with a photosynthetically active radiation-filtered waterproof sensor. To reduce shadows, all lighting was attached to an overhead ring suspended $1.8 \mathrm{~m}$ above the tank bottom and approximately $0.7 \mathrm{~m}$ outside the tank circumference. Four cone lamps with green LED ( 555-nm) clusters were mounted on the ring. The LED clusters were linked to a rheostat that was used to vary light intensity. The lights were placed directed perpendicular to the tanks to avoid glare and hot spots.

We recorded fish movements with an overhead video camera (Ikegami Electronics, Inc., Mahwah, NJ) and under infrared illumination. Infrared illumination ranged from $760-880 \mathrm{~nm}$, which is a range undetectable by Pacific halibut (John, 1964; Higgs and Fuiman, 1996; Brill et al., 2008). Infrared lights were placed below the bottom of the tank and provided a silhouette of the fish; these lights were left on for all experimental trials, regardless of the light treatment being used. Each experimental tank had a clear Plexiglas tube placed in the middle that held a white fishing jig that was attached to the ceiling with a counter-weighted line and to the bottom of the tank with an elastic band. The bottom $20 \mathrm{~cm}$ of the Plexiglas tubes were covered with black tape, such that the jig would not be visible to the fish when not in use.

Fish were allowed to recover for at least $48 \mathrm{~h}$ after exposure to simulated sunlight before use in further trials. Each pair of fish was tested at all 6 levels of illumination: 2 illumination levels on each of the first 2 days, and a single illumination level on the last day. The illumination level was set with the rheostat and fish were allowed to acclimate for $2 \mathrm{~h}$ before the trial began, $2 \mathrm{~h}$ were allowed between trials, and the order of testing with respect to illumination level was randomized. A trial at each illumination level consisted of two 5-min periods before and after presentation of the visual stimulus (white jig). After the first 5-min period, the jig was moved up and down rapidly (within the Plexiglas tube) for $60 \mathrm{~s}$ and then allowed to sink back below the masked bottom of the Plexiglas tubes, where it was out of sight. Each minute was split into 10 -s intervals and scored as to whether the pair of fish reacted to the visual stimuli. A reaction was considered positive if the fish either 1) moved one body length, 2) made oral contact with the column while attempting to bite at the jig, or 3) re-oriented itself such that the long axis of the fish was pointing toward the jig $\left(\sim 10^{\circ}\right)$.

\section{Scoring behavior of fish}

Scores were recorded as either 0 (no reaction by either fish), 1 (reaction by one fish), or 2 (reaction by both fish). For each 1-min trial, the 10-s scores were summed to arrive at an activity index. We compared activity indexes of fish exposed to simulated sunlight and control fish over time at each light level by using repeated measures ANOVA ( $n=6-9)$. Where ANOVA results indicated significant differences, a Tukey's HSD was used to determine differences between group means. During the scoring process and in preliminary analysis it became apparent there was no difference between the lowest light levels $\left(1 \times 10^{-5}, 1 \times 10^{-6}\right.$, and $1 \times 10^{-7} \mathrm{\mu mol} \cdot \mathrm{m}^{-2} \cdot \mathrm{s}^{-1}$ and complete darkness). Hence, we decided to show only the highest 4 light intensities $\left(1 \times 10^{-3}, 1 \times 10^{-4}, 1 \times 10^{-5}\right.$, and $\left.1 \times 10^{-6} \mu \mathrm{mol} \cdot \mathrm{m}^{-2} \cdot \mathrm{s}^{-1}\right)$.

\section{Results}

\section{Electroretinography experiment}

At the same light intensities, voltages measured on the corneal surface of the right eyes of control fish were significantly higher than those measured on the corneal surface of left eyes. This finding was manifest by a significant interaction between eye (left vs. right) and light intensity in our ANOVA $\left(F_{[16,32]}=4.18, P<0.0001\right)$. The difference in the responses of right and left eyes increased with increasing light intensities (Fig. 1). When voltage data for each fish were converted to $\mathrm{p}$ - 


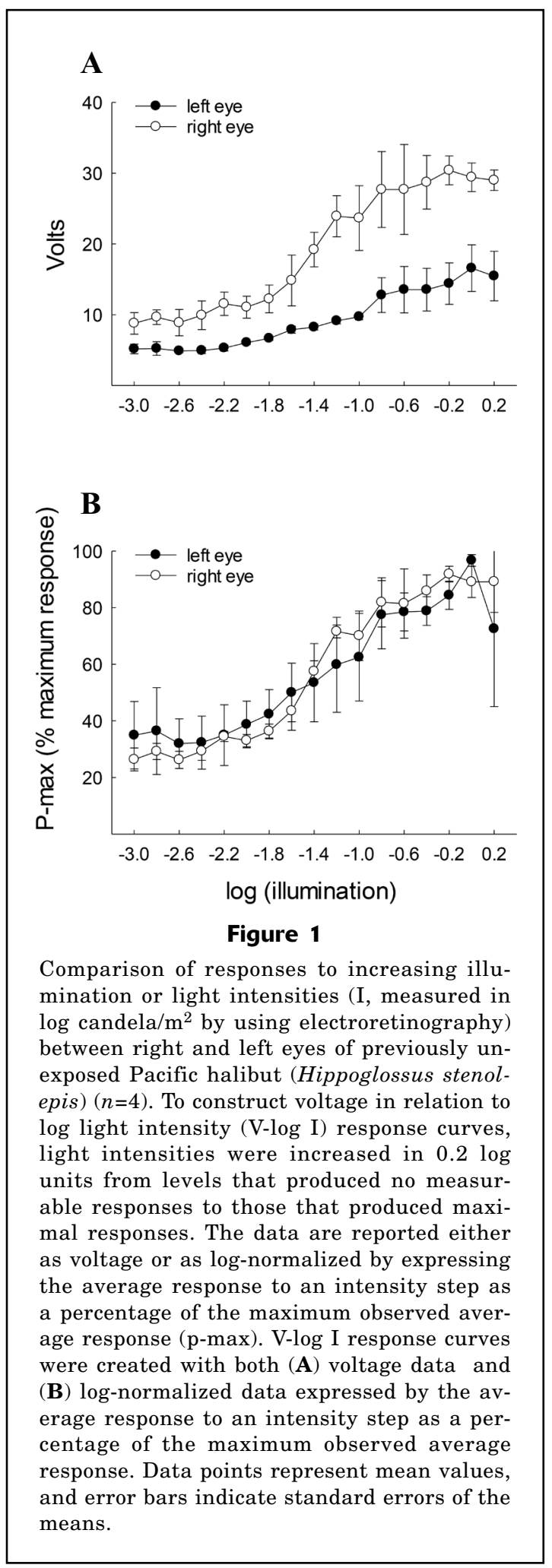

max, a significant difference was no longer present between left and right eyes $\left(F_{[1,2]}=0.00, P=0.963\right)$, nor was there a significant interaction between eye and light intensity $\left(F_{[16,32]}=0.90, P=0.575\right)$. P-max contin- ued to increase with increasing test light level $\left(F_{16,32]}\right.$ $=17.68, P<0.001$ ).

Exposure to simulated sunlight for 15 min resulted in a visual deficit that did not improve during the 10 weeks of recovery. Voltages measured from the right eyes of control fish (i.e., no exposure to simulated sunlight) were generally greater than those of the right eyes of fish that were exposed to simulated sunlight and allowed to recover for $2-10$ weeks. This was particularly evident at lower test light levels, as evidenced by a significant interaction between treatment and light intensity (Fig. $2 \mathrm{~A} ; F_{[64,272]}=1.55, P=0.009$ ). Conversion of voltages to $\mathrm{p}$-max did not appreciably change this relationship (Fig. 2B). Again, there was a significant interaction between treatment and light intensity $\left(F_{[64,272]}=2.04, P<0.001\right)$.

There were significant differences in light intensities required to produce a response $50 \%$ of maximum $\left(F_{[4,17]}=11.4, P<0.001\right)$ between treatments (control, and 2, 4, 6 and 10-weeks recovery) (Fig. 3). The light intensity required to produce a response $50 \%$ of maximum was significantly lower for control fish, than for fish in any of the recovery treatments (Tukey's HSD: $P<0.05$ ). Among the recovery treatments, the light intensity required to produce a response $50 \%$ of maximum increased over the 10-week recovery period and was lower at week 2 than at week 10 (Tukey's HSD: $P<0.05$ ). The light intensity required to produce a response $50 \%$ of maximum at week 2 did not differ from those at either weeks 4 or 6 , and similarly, the response at week 10 did not differ from responses at weeks 4 or 6 (Tukey's HSD: $P<0.05$ ). In context, it took approximately 17 times the photons to produce a response of $50 \%$ of maximum in fish exposed to simulated sunlight after 10 weeks than it did for control fish.

\section{Behavioral experiment}

There was no effect of exposure to simulated sunlight on the behavioral response of Pacific halibut to the visual cues associated with a simulated prey $\left(F_{[27,324]}\right.$ $=0.40, P=0.539$ ). This lack of difference between control and treated fish was consistent throughout the trials, as well as across ambient light levels, because ANOVA showed no significant interactions between treatment (control vs fish exposed to simulated sunlight) and any of the other factors (e.g., time, ambient light level). Pacific halibut were generally active and responded strongly to the appearance of prey (presented at the beginning of minute 6 ) at the highest ambient illumination $\left(3 \times 10^{-3} \mathrm{\mu mol} \cdot \mathrm{m}^{-2} \cdot \mathrm{s}^{-1}\right)$, but responsiveness progressively declined at lower ambient light levels (Fig. 4). This finding is supported by a significant interaction between time and ambient light level in our ANOVA for Pacific halibut activity $\left(F_{[27,324]}=4.16, P<0.001\right)$. At the 2 highest ambient light levels, fish would orient themselves toward the simulated prey when it appeared, swim toward it, and repeatedly strike at the sides of the Plexiglas tube containing the simulated prey. This behavior was characterized by a sharp in- 


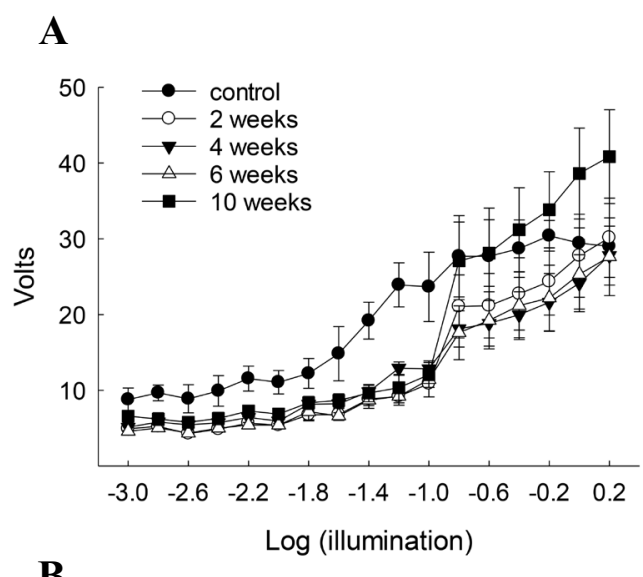

B

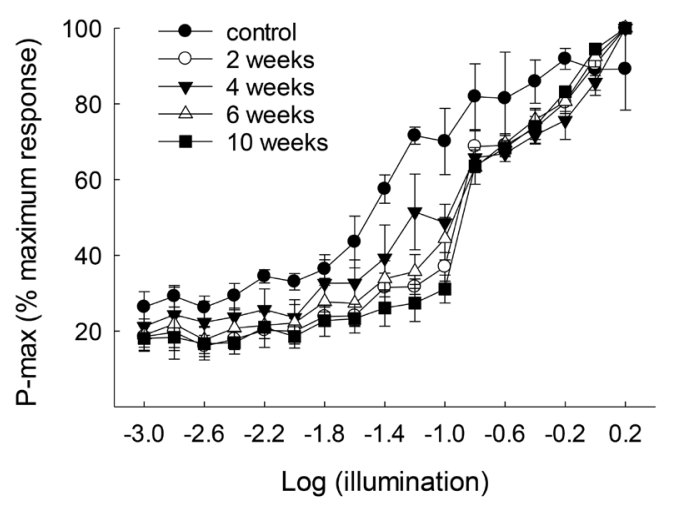

Figure 2

Comparison of responses to increasing illumination or light intensities (I, measured in log candela $/ \mathrm{m}^{2}$ by using electroretinography) between a control group of Pacific halibut (Hippoglossus stenolepis) and another group of $\mathrm{Pa}-$ cific halibut $2,4,6$, and 10 weeks after light exposure $(n=8-10)$. To construct voltage in relation to log light intensity (V-log I) response curves, light intensities were increased in 0.2 log-unit steps from levels that produced no measurable responses to those that produced maximal responses ( $p$-max). The data are reported both as voltage and log-normalized by expressing the average response to an intensity step as a percentage of the maximum observed average response. V-log I response curves were created by using voltage data and log-normalized data expressed by the average response to an intensity step as a fraction of the maximum observed average response. All data points are those recorded from the right eye. Data points represent means \pm standard error.

crease in activity from minute 5 to 6 (Tukey's HSD: $P<0.05$, for $3 \times 10^{-3}$ and $3 \times 10^{-4} \mu \mathrm{mol} \cdot \mathrm{m}^{-2} \cdot \mathrm{s}^{-1}$ ) (Fig $4, \mathrm{~A}$ and $\mathrm{B})$. This response diminished as ambient light levels decreased, and no significant increase in activity was observed from minute 5 to 6 at the 2 lowest ambi-

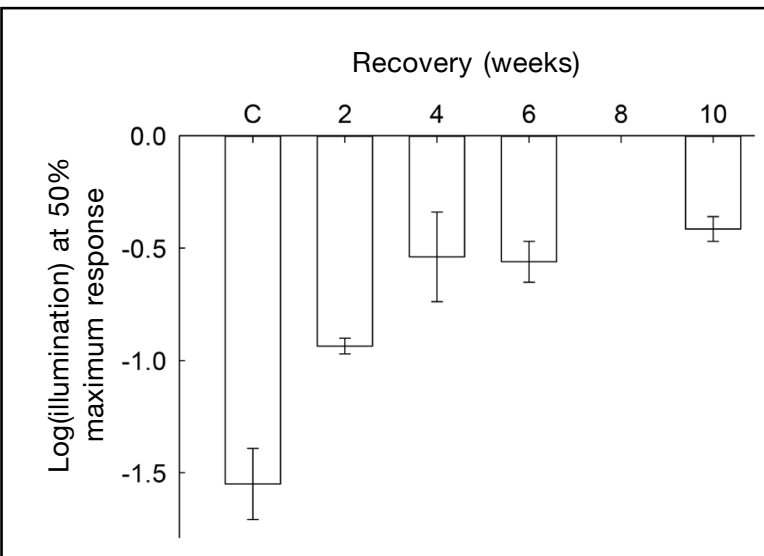

Figure 3

Comparison of responses to increasing illumination or light intensities (I, measured in $\log$ candela $/ \mathrm{m}^{2}$ ) by using electroretinography [ERG] between a control group of Pacific halibut (Hippoglossus stenolepis) and another group of Pacific halibut after 2, 4,6 , and 10 weeks of recovery from light exposure $(n=8-10)$. To construct voltage in relation to log light intensity (V-log I) response curves, light intensities were increased in 0.2 log-unit steps from levels that produced no measurable responses to those that produced maximal responses. The data were log normalized by expressing the average response to an intensity step as a fraction of the maximum observed average response. Each curve was then fitted with a second-order polynomial equation because the ERG response curves generally indicated a sigmoid response to light intensities. Light intensities required to produce a response $50 \%$ of the maximum response were taken from the predicted values produced from the quadratic equation for each model. All data points were those recorded from the right eye. Data points represent means, and error bars indicate standard errors of the means.

ent light levels (Tukey's HSD: $P>0.05$, for $3 \times 10^{-5}$ and $\left.3^{\times} 10^{-6} \mathrm{\mu mol} \cdot \mathrm{m}^{-2} \cdot \mathrm{s}^{-1}\right)$ (Fig $4, \mathrm{C}$ and $\left.\mathrm{D}\right)$.

\section{Discussion}

Prior research (Brill et al., 2008) has shown that exposure to simulated sunlight (i.e., imitating the situation experienced on the deck of a vessel) impairs the retinal function of Pacific halibut. The authors speculated that exposure to simulated sunlight resulted in damage and apoptosis of photoreceptor cells containing the longer wavelength (520-540-nm) absorbing visual pigments. A predominance of receptors with maximal sensitivity in the green wavelengths is characteristic of coastal and continental shelf species (Levine and MacNichol, 1979; Bowmaker, 1990). If permanent, a deficit in these retinal receptors could have negative consequences for post release foraging success, somatic growth, reproductive success, and ultimately survival. 


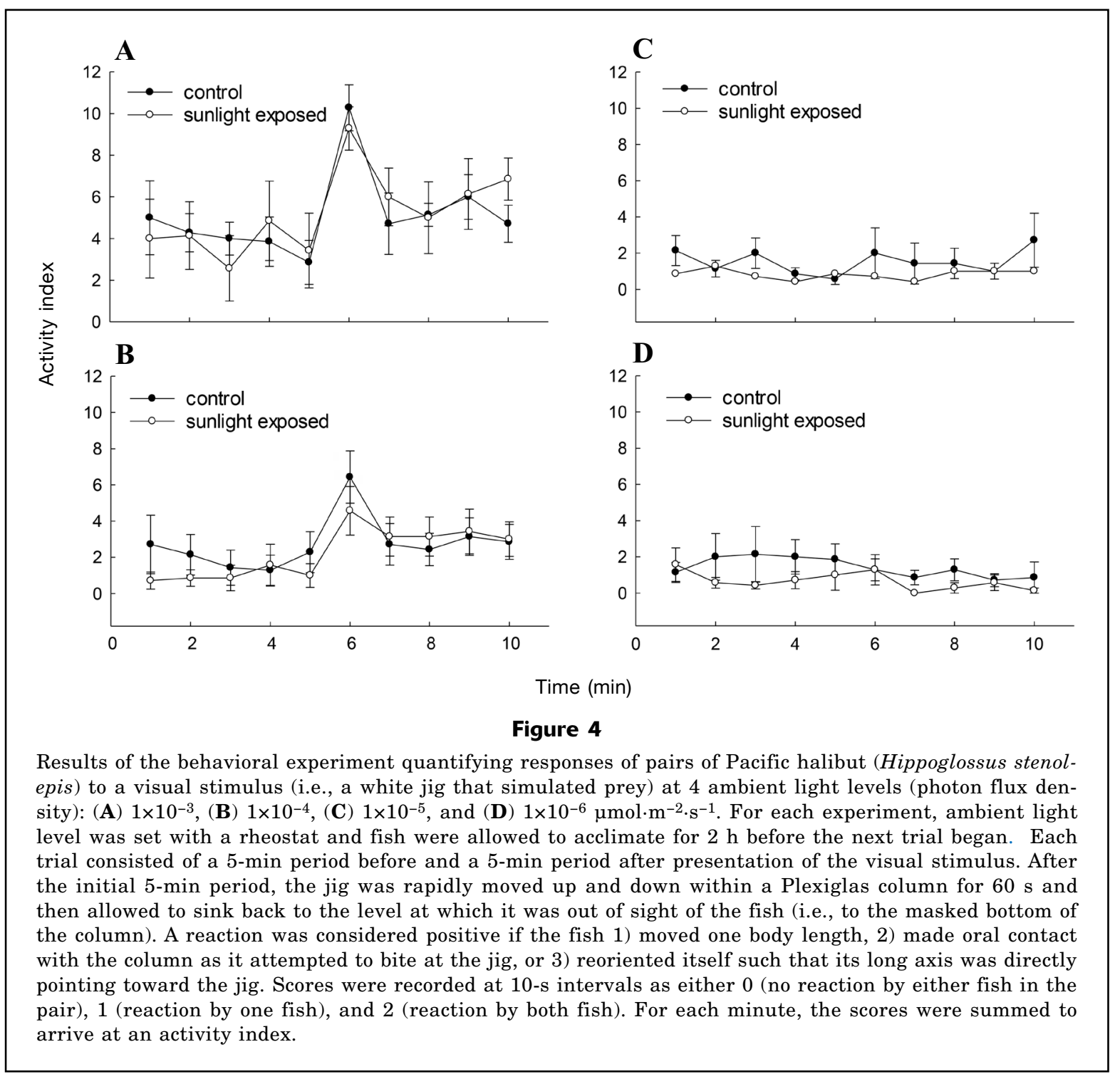

Using both ERG and a behavioral assay, we tested the hypothesis that Pacific halibut recover from retinal damage and visual function resulting from exposure to direct sunlight. Our ERG data indicated damage to the Pacific halibut visual system and no significant recovery during the 10 weeks after exposure. Even after 10 weeks, it took approximately 17 times the light intensity to elicit a response $50 \%$ of maximum than with control fish. This result equates to an approximate $94 \%$ reduction in retinal sensitivity. In contrast, our behavior assay (which occurred 2-6 d after exposure to simulated sunlight) could not reveal impairment of the ability of Pacific halibut to detect visual cues associated with simulated prey across a broad range of ambient light levels.

Electroretinography is a procedure in which the summed electrical responses from the retinal photoreceptors are recorded by placing electrodes on the cor- neal surface and skin adjacent to the eye. In our study, we exposed fish to 15 min of simulated sunlight, an intensity equivalent to ambient sunlight under clear skies at noon (Newport, Oregon, 5 October 2007; the same exposure used by Brill et al., 2008). Light-exposed fish required approximately 5 times the amount of light to generate an ERG response equal to control fish. This was manifest as a depression in both voltage and p-max voltage plotted against log illumination. These curves remained depressed over a 10 -week post exposure period, compared with controls that indicated no recovery of retinal sensitivity. Brill et al. (2008) speculated that the mechanism of damage was disruption of photoreceptor cells and predicted that the process would be progressive and permanent. Our ERG data support this contention. The illumination required to stimulate a $50 \%$ maximum response, shows that vision deteriorated from 2 weeks to 10 weeks 
after exposure, indicating a progressive worsening of Pacific halibut retinal sensitivity over time. In an environmental context, a sunlight exposed Pacific halibut would have to move to water that is $18 \mathrm{~m}$ shallower to have the same visual acuity as that of an unexposed fish, assuming a light extinction coefficient of 0.15 (e.g., simulating typical conditions in the Gulf of Alaska). This level of illumination would potentially result in a shoaling effect among fish discarded as bycatch. Our data further indicate that the visual deficit associated with sunlight exposure was most pronounced at the low end of the Pacific halibut visual range. As a consequence, fish captured in and subsequently returned to relatively shallow well-lit waters may be less affected than fish captured from and then returned to deeper water, where impaired fish may be at the limit of their range of visual sensitivity. Whether or not discarded Pacific halibut move to shallower water to mitigate visual impairments could be tested in future research with mark-recapture techniques. It should be noted that Pacific halibut size generally increases with depth. The fish used in our ERG were 2 year olds and therefore were smaller than most fish encountered in commercial fisheries. Although we have no reason to believe that the visual systems of our fish differed from those of larger Pacific halibut, future work in this area would benefit from an examination of a wider range of fish sizes.

The impairment of retinal sensitivity revealed by ERG contrasts with the results from our behavioral assay that produced no statistical evidence of significant visual impairment associated with exposure to simulated sunlight. The simulated prey bobbed up and down within a clear Plexiglass tube that minimized cues associated with water movements and the possibility that Pacific halibut would respond to nonvisual cues. The fact that the responsiveness of fish, as measured by activity, decreased with decreasing ambient light levels clearly indicates that Pacific halibut use vision to detect prey. Yet, across the range of ambient light levels there were no consistent statistical differences between control fish and those exposed to simulated sunlight, with the possible exception of a slight reduction of behavioral activity (i.e. movement, bait strike, etc) among the latter at an ambient light level of $1 \times 10^{-4}$ $\mu \mathrm{mol} \cdot \mathrm{m}^{-2} \cdot \mathrm{s}^{-1}$ (Fig. 4B). Pacific halibut are visual predators and at light levels of $1 \times 10^{-4} \mu \mathrm{mol} \cdot \mathrm{m}^{-2} \cdot \mathrm{s}^{-1}$ primarily use visual cues to locate and attack prey, shifting to tactile and olfactory cues as light levels fall below $1 \times 10^{-5} \mathrm{\mu mol} \cdot \mathrm{m}^{-2} \cdot \mathrm{s}^{-1}$ (Hurst et al., 2007). For immobile baits, Pacific halibut feeding performance is likewise facilitated by vision (Stoner, 2003). We initially reasoned that the threshold ambient light level for visual foraging would be that at which a deficit would be most pronounced. It is possible that we performed tests over too wide a range of ambient light levels. For example, we might have seen a difference between sunlightexposed and control fish by testing over finer gradations of ambient light levels between $1 \times 10^{-5}$ to $1 \times 10^{-4}$ $\left.\mu \mathrm{mol} \cdot \mathrm{m}^{-2} \cdot \mathrm{s}^{-1}\right)$. Additionally, conditions in this behavior- al assay were designed to maximize the probability of prey detection. The Pacific halibut were in close proximity to the simulated prey in clear water. Had the distance between Pacific halibut and simulated prey been greater, or the water more turbid, the demands upon the visual system may have been magnified in such a way that more clearly showed impairment.

An ancillary discovery from our work was the difference between left and right eye function in Pacific halibut. Left eyes had consistently depressed V-log I curves than right eyes (i.e., the former are less light sensitive than the latter). Pacific halibut are righteyed flounders; the left eye migrates to the right side of the head during larval development and metamorphosis. This "tortured ontogeny" in flatfish may add constraints to optic nerve function. To our knowledge, however, little research exists on retinal anatomy or physiology in larval flatfish, beyond documentation of eye development of Atlantic halibut (Hippoglossus hippoglossus) and other flatfish at settlement (Kvenseth et al., 1996; Friedman, 2008). Although V-log I curves differed between left and right eyes, there were no apparent differences when responses were transformed to p-max response curves. Therefore, although voltage responses to brief light flashes from the left eyes are lower, both left and right eyes appear to otherwise function comparably. In brief, both eyes show comparable light sensitivities, although the smaller ERG response from the left eye (compared with that of the right eye) at the same light intensities implies anatomical and perhaps functional differences at the central nervous system level. Additionally, because of their unique dextral morphological features as adults, Pacific halibut may be more susceptible to injuries to their right eyes owing to hooking injuries in long-line commercial fisheries because the right eye is closer than the left eye to the jaw. This conclusion would warrant future research in hook-induced eye damage and handling practices specific to hook-and-line fisheries.

Hook-and-line fisheries, whether recreational or commercial, generally result in the rapid return of discarded fish to the water so that there is a concomitant minimal exposure to direct sunlight. In contrast, in trawl fisheries Pacific halibut may remain on deck for up 30 min and experience significant mortality (Trumble et al., 1995), although new deck sorting methods have decreased that time. For those fish that survive aerial exposure, it was postulated that sublethal effects on visual sensitivity arising from sunlight exposure could further reduce growth and survival (Brill et al., 2008). Because flicker fusion frequency (i.e., the speed of vision or the ability to detect moving objects) and light sensitivity of the Pacific halibut visual system are adapted to low-light environments (Warrant, 1999), Pacific halibut, in particular, are susceptible to retinal damage from exposure to direct sunlight than are shallow-water fish species. Our ERG data support these conclusions and are consistent with the data from Brill et al. (2008) in that we found that exposure to simulated sunlight exposure reduces retinal light sen- 
sitivity in Pacific halibut across a broad range of illuminations, and the $\sim 94 \%$ reduction in light sensitivity does not recover for during 10 weeks. Visual sensitivity appeared to be most affected at low ambient light levels. If this impairment is permanent, we speculate that fish may either make the best of a bad situation if they are released into deep waters, or attempt to move to shallower water to compensate for their visual deficit. However, these conclusions from our ERG data conflict with our behavioral data and observations, where no clear impairment in simulated prey detection was observed. We suspect that our behavioral assay may not have been ideally designed to show differences in visual sensitivity. We are not aware of any other studies that have attempted to link visual function, as measured by methods such as ERG, with behavioral performance, which ultimately determines the fitness of a species with visual deficits. This is an area of research that will be needed to assess the consequences of damage to the visual system resulting from conditions onboard vessels before discard of bycatch (Pacific halibut and other fish species), and to assess the implications of such damage for fisheries management.

\section{Acknowledgments}

We thank P. Iseri, M. Ottmar, and S. Haines for assistance with the collection, care, and husbandry of fish. We also wish to acknowledge 3 anonymous reviewers for their insightful comments and editorial assistance on an early version of the manuscript.

\section{Literature cited}

Alverson, D. L., M. H. Freeberg, S. A. Murawski, and J. G. Pope.

1994. A global assessment of fisheries bycatch and discards. FAO Fish. Tech. Pap.339, 233 p. FAO, Rome.

Baker, M. R., and D. E. Schindler.

2009. Unaccounted mortality in salmon fisheries: nonretention in gillnets and effects on estimates of spawners. J. Appl. Ecol. 46:752-761. Article

Benaka, L. R., L. Sharpe, L. Anderson, K. Brennan, J. E. Budrick, C. Lunsford, E. Meredith, M. S. Mohr, and C. Villafana.

2014. Fisheries release mortality: identifying, prioritizing, and resolving data gaps. NOAA Tech. Memo. NMFS-F/ SPO-142, $55 \mathrm{p}$.

Bowmaker, J. K.

1990. Visual pigments of fishes. In The visual system of fish (R. Douglas and M. Djamgoz, eds.), p. 81-107. Chapman and Hall, London.

Brill, R., C. Magel, M. Davis, R. Hannah, P. Rankin.

2008. Effects of rapid decompression and exposure to bright light on visual function in black rockfish (Sebastes melanops) and Pacific halibut (Hippoglossus stenolepsis). Fish. Bull. 106:427-437.

Brown, K. T.

1968. The electroretinogram: its components and their origin. Vision Res. 8:633-677. Article
Davis, M. W.

2002. Key principles for understanding fish bycatch discard mortality. Can. J. Fish. Aquat. Sci. 59:18341843. Article

Davis, M. W., and B. L. Olla.

2001. Stress and delayed mortality induced in Pacific halibut by exposure to hooking, net towing, elevated seawater temperature and air: implications for management of bycatch. North Am. J. Fish. Manage. 21:725-732. Article

Davis M. W., and C. B. Schreck.

2005. Responses by Pacific halibut to air exposure: lack of correspondence among plasma constituents and mortality. Trans. Am. Fish. Soc. 134:991-998. Article

Friedman, M.

2008. The evolutionary origin of flatfish asymmetry. Nature 454:209-212. Article

Higgs, D. M., and L. A. Fuiman.

1996. Light intensity and schooling behaviour in larval gulf menhaden. J. Fish. Biol. 48:979-991. Article

Hurst T. P., C. H. Ryer, J. M. Ramsey, and S. A. Haines.

2007. Divergent foraging strategies of three co-occurring north Pacific flatfishes. Mar. Biol. 151:1087-1098. Article

John, K. R.

1964. Illumination, vision, and schooling of Astyanax mexicanus (Filipi). J. Fish. Res. Board Can. 21:1453-1473. Article

Kaimmer, S. M., and R. J. Trumble.

1998. , condition, and mortality of Pacific halibut bycatch following careful release by Pacific cod and sablefish longline fisheries. Fish. Res. 38:131-144. Article

Kvenseth, A., M., K. Pittman, and J. V. Helvik.

1996. Eye development in Atlantic halibut (Hippoglossus hippoglossus): differentiation and development of the retina from early yolk sac stages through metamorphosis. Can. J. Fish. Aquat. Sci. 53:2524-2532. Article

Lalli, C. M., and T. R. Parsons.

1997. Biological oceanography: an introduction, 2nd ed., 324 p. Elsevier Butterworth-Heineman, Oxford, UK.

Levine, J. S., and E. F. MacNichol Jr.

1979. Visual pigments in teleost fishes: effects of habitat, microhabitat, and behavior on visual system evolution. Sens. Process. 3:95-131.

Loew, E. R.

1976. Light, and photoreceptor degeneration in the Norway lobster, Nephrops norvegicus. Proc. R. Soc. Lond., B. 193:31-44. Article

Meka, J. M., and F. J. Margraf.

2007. Using a bioenergetic model to assess growth reduction from catch-and-release fishing and hooking injury in rainbow trout, Oncorhynchus mykiss. Fish. Manage. Ecol. 14:131-139. Article

Meyer-Rochow, V. B.

1994. Light-induced damage to photoreceptors of spiny lobsters and other crustaceans. Crustaceana 67:95-109.

Morgan, M. J., C. E. Wilson, and L. W. Crim.

1999. The effect of stress on reproduction in Atlantic cod. J. Fish Biol. 54:477-488. Article

Ryer, C. H.

2002. Trawl stress and escapee vulnerability to predation in juvenile walleye pollock: is there an unobserved bycatch of behaviorally impaired escapees? Mar. Ecol. Prog. Ser. 232:269-279. Article

2004. Laboratory evidence for behavioural impairment of 
fish escaping trawls: a review. ICES J. Mar. Sci. 61:11571164. Article

Sokal, R. R., and F. J. Rohlf.

1969. Biometry, 776 p. W.H. Freeman and Co., San Francisco, CA.

Stoner, A. W.

2003. Hunger and light level alter response to bait by Pacific halibut: laboratory analysis of detection, location, and attack. J. Fish Biol. 62:1176-1193. Article

Trumble, R. J., G. H. Williams, and S. E. Hughes.

1995. Methods to improve survival of Pacific halibut by- catch discarded from a factory trawler. In Proceedings of the international symposium on North Pacific flatfish. Alaska Sea Grant College Program Rep. AK-SG-95-04, p. 591-610, Univ. Alaska Fairbanks, Fairbanks, AK.

Warrant, E. J.

1999. Seeing better at night: life style, eye design and the optimum strategy of spatial and temporal summation. Vision Res. 39:1611-1630. Article

Wu, J., S. Seregard, and P. V. Algvere. 2006. Photochemical damage of the retina. Surv. Ophthalmol. 51:461-481. Article 